\title{
Are consultants in Colombo, Sri Lanka satisfied with their job?
}

\author{
S. Cooray ${ }^{1}$, K. Wijewardene ${ }^{1^{*}}$, A. Dawson ${ }^{2}$ \\ ${ }^{1}$ Department of Community Medicine, Faculty of Medical Sciences, University of Sri Jayewardenepura, Nugegoda, Sri Lanka; \\ *Corresponding Author: kumuduwije@gmail.com \\ ${ }^{2}$ Health Services and Practice, Faculty Nursing, Midwifery and Health University of Technology, Sydney, Australia
}

Received 13 July 2012; revised 10 August 2012; accepted 23 August 2012

\section{ABSTRACT}

Introduction: Job stress and job satisfaction play a key role in the work environment of an organization. These influence the behaviour of a doctor towards his or her co-workers, administration and, most importantly towards the patients. Objective: To assess job stress among consultants working in Colombo group of hospitals and to identify the factors that affect job satisfaction. Methods: A descriptive cross sectional study was conducted by using postal questionnaire on 262 consultants working in Colombo group of hospitals. Hospital consultants job stress and job satisfaction questionnaire developed by Amanda Ramirez et al. was used with their permission. Results: Of the 262 questionnaires mailed 171 were returned. Of total responded $84.6 \%$ reported extremely satisfied or satisfied with their work. Nearly $92 \%$ agreed intellectual stimulation by teaching contributed to their job satisfaction. Nearly $80 \%$ reported having a high level of responsibility, being perceived to do the job well by the colleagues, being able to bring about positive changes to the unit, having a high level of autonomy contributed to their job satisfaction. Poor administration and lack of facilities e.g. computers, filing procedures caused job stress in $73 \%$. Threat of being sued for malpractice or having to deal with distressed relatives did not contribute to stress in nearly $\mathbf{8 0 \%}$. Conclusion: In Sri Lanka nearly $85 \%$ consultants reported they were satisfied with their job and teaching medical undergraduates and post graduates was one of the major contributory factors. However $73 \%$ indicated factors such as lack of resources, and poor administration cause stress at work. Providing computers and basic stationery for patient documentation and efficient and effective administration will improve the work output of consult- ants by reducing their stress levels.

Keywords: Sri Lanka; Hospital Consultants; Stress; Satisfaction

\section{INTRODUCTION}

In Sri Lanka compared to most South Asian countries vital statistics such as maternal mortality ratio, infant mortality rate and life expectancy are low and almost similar to developing countries. The state health care services are free and patient can seek health care from any hospital from district, general, provincial or national hospital. Although referral system operates patients can bypass these and seek any hospital they wish [1]. In Sri Lanka there are 1291 medical consultants to serve 21 million population. The total number of doctors working in state hospitals are nearly 11,150 [1]. Colombo is the capital of Sri Lanka. Doctors are allowed by the state to do private practice consultations for a fee after $4 \mathrm{pm}$ or before 8 am on week days, Saturdays after $12 \mathrm{pm}$, Sundays and on public holidays. All consultants have several junior doctors working under them specially in Colombo group of hospitals, (senior registrars, registrars, senior house officers and house officers) [1]. They are also expected to teach medical undergraduates and train post graduates.

In the Colombo group of hospitals consultants are over loaded with service commitments and trainings. Most patients who are in critical condition and cannot be treated at provincial hospitals are transferred to Colombo group of hospitals mainly National Hospital. In addition patients also from various regions in Sri Lanka seek services from these hospitals as they assume they will get better care and treatment As the staffs who is working in these hospitals are senior they also have to attend to medical undergraduate and post graduate exams and national health policy reform committees and professional capacity building meetings. In addition to all these daily commitments; they do private practice as the state take-home salary is not adequate. Most consultants practice in the private sector 
from $4.30 \mathrm{pm}$ to 9 - $10 \mathrm{pm}$ or some till midnight and during most weekends. With this work load they also have to attend to family and social obligations. Therefore Colombo group of hospital consultants have more responsebility and accountability which can cause stress and dissatisfaction.

Job stress and job satisfaction play a key role in the work environment of an organisation. They influence the behaviour of a person towards his or her co workers, administration and in the case of a doctor, most importantly towards his patients. Job stress is the physical and emotional response which occurs when the requirements of job do not match the capabilities, resources or needs of the worker [2]. Doctors can have stress in addition to their personal problems due to work over load, poor working conditions, poor hospital administration and management and inefficient junior medical staff and paramedical staff.

A study conducted on "Psychological morbidity and job satisfaction in hospital consultants and intern medical officers" has shown that consultants have higher level of psychological distress than intern medical officers as well as a higher level of work demands [3]. Consultants are involved in the process of critical decision making. Therefore their psychological wellbeing is important as it may compromise the quality of patient care. Most of the current research on doctors' psychological wellbeing has been centred on junior doctors. Consultants are shown to be subjected to stress due to occupational factors just as much as junior doctors.

Job satisfaction was shown to have a protective effect against the negative consequences of work stress according to a study done among 2400 Dutch medical specialists by Visser et al. [4]. There was a high level of stress despite that the Dutch specialists were highly satisfied with their work. According to the results $81 \%$ reported high job satisfaction. Lack of professional autonomy, fear of lawsuits and job insecurity contributed to the stress.

A study done by Ramirez et al., on the mental health of hospital consultants (gastroenterologists, surgeons, radiologists and oncologists) [5] to examine the relationship between consultants' mental health and their job stress and satisfaction revealed that job satisfaction significantly protected consultants' mental health against job stress. Work overload was identified as major contributor to overall job stress.

Ofili et al. reported job satisfaction and its relationship with psychological disorder amongst Nigerian doctors [6]. The study showed $34 \%$ of doctors were dissatisfied and $33 \%$ of satisfied doctors indicated external sources as a factor for stress. It was concluded that Nigerian doctors had a high rate of job dissatisfaction than European or American doctors. According to the results of a study conducted in Pakistan 56\% of doctors were not satisfied with their level of income and 92\% was not satisfied with the present service structure. None of the senior registrars and associate professors was satisfied with their career prospects in Pakistan [7].

\section{OBJECTIVE}

To assess job stress among consultants working in Colombo group of hospitals and to identify the factors that affect job satisfaction.

\section{METHODS}

A Descriptive cross sectional study was conducted by using a questionnaire.

The questionnaire along with a covering letter explaining the purpose of the research was mailed to 262 consultants from all major and minor specialities working in Colombo group of hospitals. ("Hospital consultants job stress and job satisfaction questionnaire.” developed by Amanda Ramirez et al. [5] was used. Permission was obtained to use this questionnaire from the author). This questionnaire was formulated to be used for local suitability and comprised 22 questions to assess job satisfaction and 25 for stress. Names and speciality were not included to maintain anonymity. The survey tool was pre tested prior to posting. A self addressed stamped envelope was included with the questionnaire to return the filled forms. Each question was measured on likert scale of 0 to 3 where "0" was represented as "not at all", and " 3 " was represented as a lot. The total score for satisfaction was 66 while the maximum score for stress was 75 . The questions included for satisfaction were having good relationship with patients, staff members, being expert in the speciality, intellectual stimulation from teaching etc. The questions that assessed stress were inadequate facilities, poor administration, having great volume of work, insufficient time for teaching etc. The questionnaire had two final questions assessing overall satisfaction and stress measured on a scale of $5(0$ - 4) where 4 represented extremely satisfied or extremely stressful.

\section{RESULTS}

Of the 262 questionnaires mailed 171 were returned. The response rate was $65 \%$. Of them $77 \%$ were clinicians and $23 \%$ were doing laboratory based work. Of total responded $84.6 \%$ reported extremely satisfied or satisfied with their work. Having good relationships with their patients was indicated by $84 \%$ of clinicians as a factor for job satisfaction. Nearly $80 \%$ reported having a high level of responsibility, being perceived to do the job well by the colleagues, being able to bring about positive changes to the unit, having a high level of autonomy and having variety in the job contributed to their job satisfaction (Figure 1). 
Nearly 92\% agreed intellectual stimulation by teaching contributed to their job satisfaction. Having the opportunity to practice medicine privately contributed to job satisfaction in $63 \%$. Of the total samples only $27 \%$ indicated that they were extremely stressful or stressful. Poor administration and lack of facilities e.g. computers, filing procedures caused job stress in 73\% (Figure 2). The great volume of work contributed stress only in $56 \%$. Forty per- cent consultants identified that, disruption of home life through spending long hours at work contributed "a lot" and "quite a bit" to the job stress and 54\% indicated having insufficient formalized time for teaching, training and research as stressful factor.Dealing with the threat of being sued for malpractice or having to deal with distressed angry or blaming relatives did not contribute to stress in nearly $80 \%$.

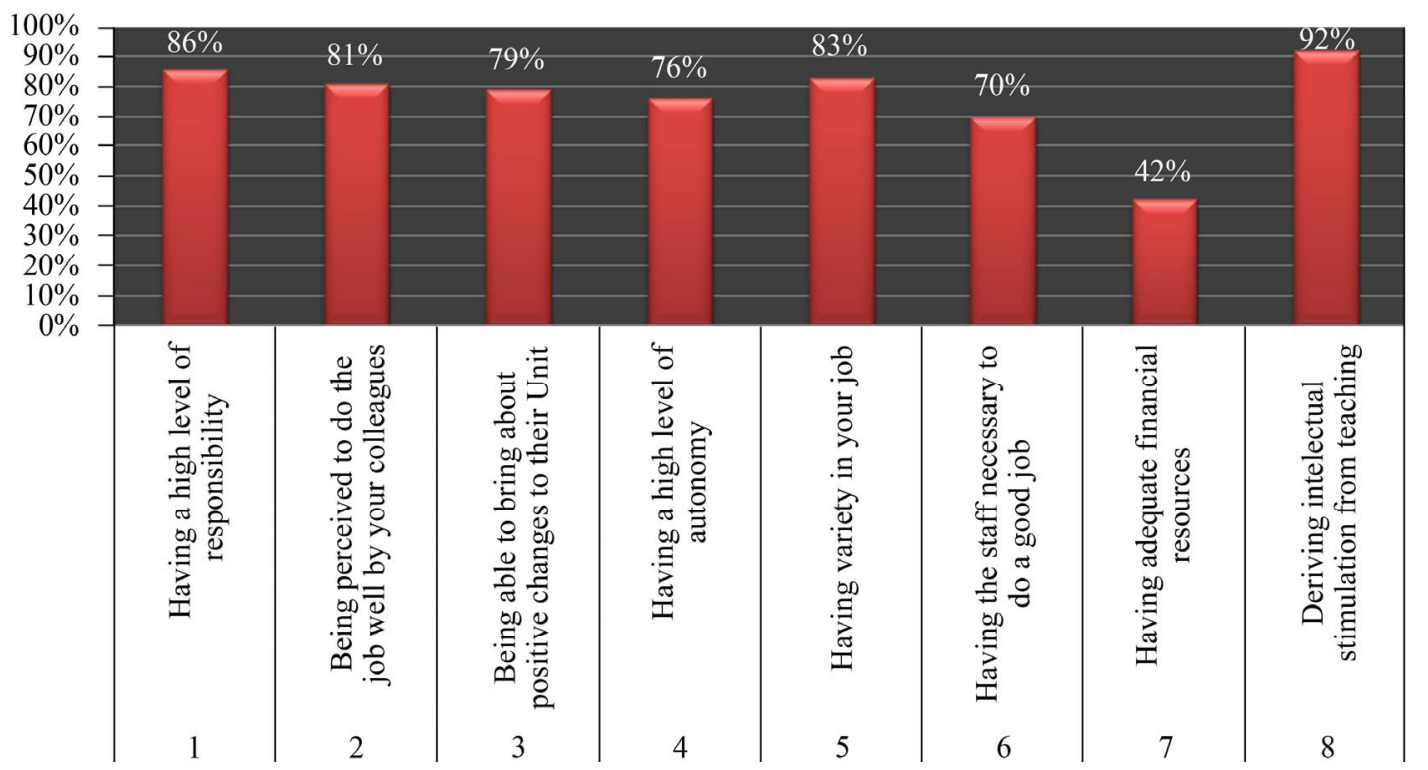

Figure 1. Factors responsible for job satisfaction.

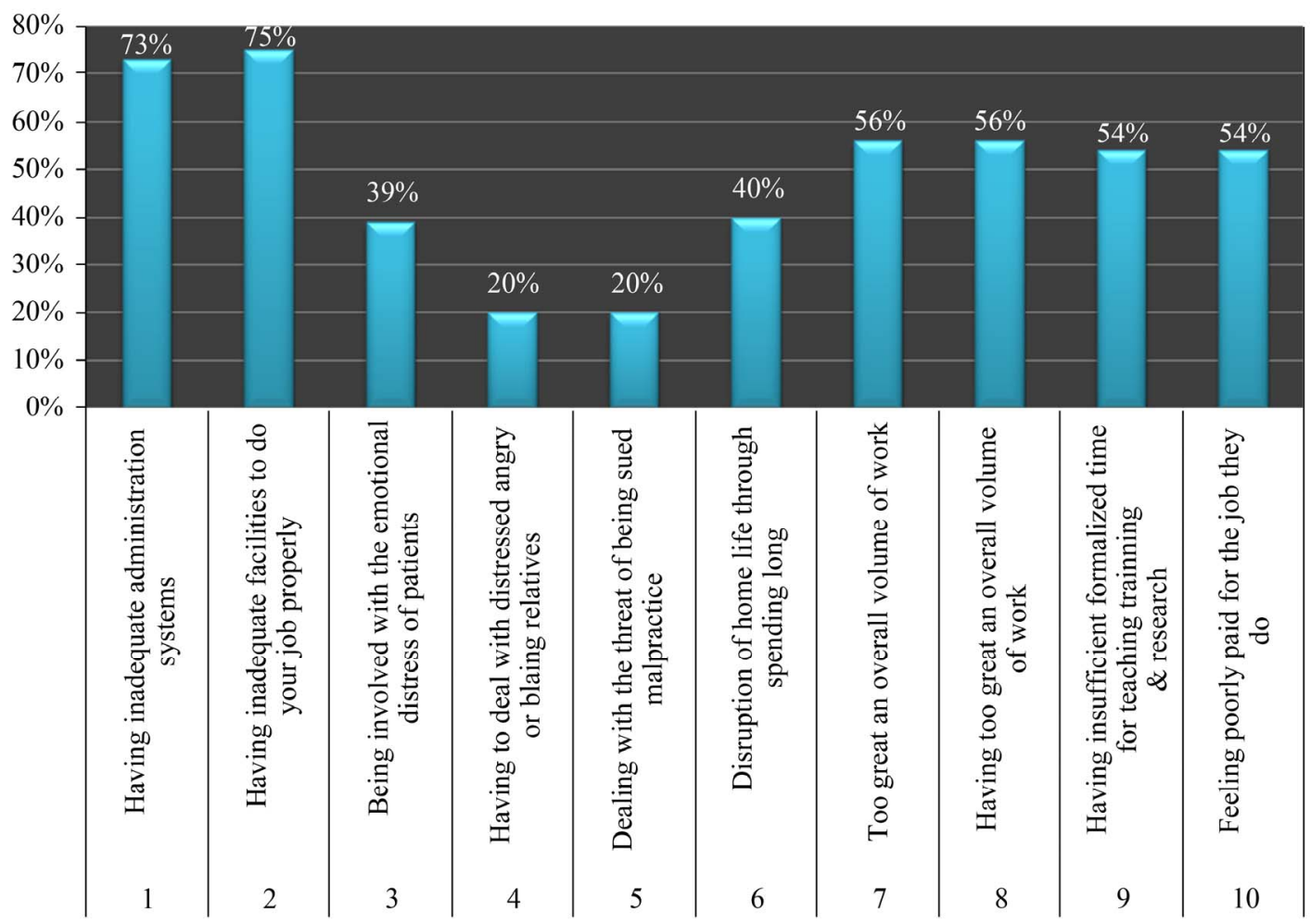

Figure 2. Factors responsible for stress. 


\section{DISCUSSION}

The sources which measured professional esteem "having a high level of responsibility", "being perceived to do the job well by your colleagues", "being able to bring about positive changes to the unit" and "having a high level of autonomy" were major factors that contributed to job satisfaction in the present study. These results are similar to study done by Ramirez et al. [5]. "Having variety in your job" was also among the highest rated sources of job satisfaction in the present study and in the study done by Ramirez et al. It was an independent factor which had a major contribution to consultant's job satisfaction. Teaching was shown to be a source of satisfaction and a high proportion of those who found satisfaction in teaching were overall satisfied with their work.

Having the opportunity to practice medicine privately was also cited as source of job satisfaction. These results are similar to the study done in Egypt where the opportunity of doing private work was found as a predictor for job satisfaction [8].

The main factor that contributed to job stress was poor hospital administration and lack of facilities for documentation and inadequate facilities to do the job properly. In the study done in UK by Ramirez et al., also found the same factors responsible for stress at work [5]. Whether developing or developed country the factors causing stress seem to be similar.

"Having to deal with distressed, angry or blaming relatives" and the threat of being sued for malpractice" were reported by a majority as having little effect on their job stress. In Sri Lanka suing for malpractice is very rare as health care is free and consultants are treated as infallible. A majority of patients using the free healthcare facilities in the government sector are from low economical groups where the access to information and education level is also low. Therefore they do not challenge a decision made by a doctor. In the private sector too, patients feel doctors do their best and the decisions are challenged very rarely.

Though not a majority, $40 \%$ indicated "Disruption of home life through long hours at work" (40\%) as a significant factor for stress, 56\% reported "having too great an overall volume of work" as being contributor to their job stress. Many studies have revealed heavy work load as a contributory factor for job stress and disruption of home life. In a study conducted in India in a tertiary hospital in Delhi, nearly 50\% doctors indicated dissatisfaction with the average number of working hours per day [9]. Long hours of work were identified as a major stress factor by specialist Anaesthetists in Australia [10].

\section{CONCLUSION}

In Sri Lanka the study conducted among consultants in
Colombo group of hospitals showed nearly $85 \%$ consultants were satisfied with their job, and teaching was one of the major contributory factor in addition "having a high level of responsibility", "being perceived to do the job well by your colleagues", "being able to bring about positive changes to the unit" and "having a high level of autonomy" were other factors that were responsible for job satisfaction. The factors that caused stress were the lack of resources, and poor administration. Having to deal with distressed, angry or blaming relatives or the threat of being sued for malpractice had little effect on their job stress.

\section{REFERENCES}

[1] Medical Statistics Unit Sri Lanka (2007) Annual Health Statistics 2007 Sri Lanka. Ministry of Healthcare \& Nutrition, Colombo.

[2] King, M.B., Cockroft, A. and Gooch, C. (1992) Emotional distress in doctors: Sources, effects and help sought. Journal of the Royal Society of Medicine, 85, 605-608.

[3] Kapur, N., Borril, C. and Stride, C. (1998) Psychological morbidity and job satisfaction in hospital consultants and junior house officers. British Medical Journal, 317, 511512. doi:10.1136/bmj.317.7157.511

[4] Visser, M.R.M., Smets, E.M.A., Oort, F.J. and de Haes H.C.J.M. (2003) Stress, satisfaction and burnout among Dutch medical specialists. Canadian Medical Association Journal, 168, 271-275.

[5] Ramirez, A.J., Graham, J., Richards, M.A., Cull, A. and Gregory, W.M. (1996) Mental health of hospital consultants: The effects of stress and satisfaction at work. The Lancet, 347, 724-728. doi:10.1016/S0140-6736(96)90077-X

[6] Ofili, A.N., Asuzu, M.C., Isah, E.C. and Ogbeide, O. (2004) Job satisfaction and psychological health of doctors at the University of Benin Teaching Hospital. Occupational Medicine, 54, 400-403.

doi:10.1093/occmed/kqh081

[7] Khuwaja, A.K., Qureshi, R., Andrades, M., Fatmi, Z. and Khuwaja, N.K. (2004) Comparison of job satisfaction and stress among male and female doctors in teaching hospitals of Karachi. Journal of Ayub Medical College, Abbottabad, 16, 23-27.

[8] Abdel-Rahman, A.G., Halim, A.W.E.A., Allam, M.F. and Meky, F. (2008) Low job satisfaction among physicians in Egypt. TAF Preventive Medicine Bulletin, 7, 91-96.

[9] Kaur, S., Sharma, R., Talwar, R., Verma, A. and Singh, S. (2009) A study of job satisfaction and work environment perception among doctors in a tertiary hospital in Delhi. Indian Journal of Medical Sciences, 63, 139-144. doi:10.4103/0019-5359.50762

[10] Kluger, M.T., Townend, K. and Laidlaw, T. (2003) Job satisfaction, stress and burnout in Australian specialist anaesthetists. Anaesthesia, 58, 339-345. doi:10.1046/j.1365-2044.2003.03085.x 